\title{
Evaluation of Efficacy of Pulsed Electromagnetic Field Therapy as an Adjuvant Therapy in Healing of Diabetic Foot Ulcers
}

\author{
Amareswari V.H. ${ }^{1}$, Padma K. ${ }^{2}$, Dharmarajan P. ${ }^{3}$, Shivakumar S. ${ }^{4}$, K.S. Dhilip ${ }^{5}$ \\ ${ }^{1}$ Assistant Professor, Dept of Physiology, Rajarajeswari Medical College, Bengaluru, ${ }^{2}$ Redt. Prof and Director, \\ Dept of Physiology, Madras Medical College, Chennai, Tamilnadu, ${ }^{3}$ Prof and Director, Dep of Diabetology, Rajiv \\ Gandhi Govt General Hospital, Chennai, Tamilnadu, ${ }^{4}$ Cheif Medical Officer Madras Institute of Magneto Biology \\ Chennai, Tamilnadu, ${ }^{5}$ Director Madras Institute of Magneto Biology, Chennai, Tamilnadu
}

\begin{abstract}
Background and Aim: Foot ulcer is a common complication of diabetes mellitus. The life time risk of developing foot ulcer is $25 \%$ with an annual incidence of $2-3 \%$ and may result in limb amputation if left untreated. Diabetic foot ulcers are conventionally treated with wound debridement and off loading. Proper wound healing is uncertain in conservative management of these ulcers. Pulsed Electromagnetic Field therapy is a new modality that interacts at various steps in wound healing. This study aims at evaluating the efficacy of pulsed electromagnetic field therapy as an adjunct therapy in diabetic foot ulcers. Method and materials: Thirty patients with mean duration of Diabetes $7.8 \pm 1.47 \mathrm{yrs}$, mean duration of foot ulcer $4.9 \pm 1.2$ months with Wagner's grade 1 and 2 were subjected to Pulsed electromagnetic field for $45 \mathrm{~min} /$ day for 30 days Statistical Analysis: Data was analysed using student paired $t$-test Results: The patients showed overall $66 \% \pm 15 \%$ reduction in the wound surface area. Less than $50 \%$ reduction is reported in 2 of the patients. About 50-59\% reduction is noted in 6 patients, 11 patients showed $60-69 \%$ reduction, 7 patients showed $70-$ $79 \%$ reduction, 2 patients more than $90 \%$ reduction and 2 patients showed $80-89 \%$ reduction in the wound area. None of them reported any side effects. P value of $<0.05$ was taken to be significant. Discussion and conclusion: Significant reduction in wound surface area observed could be due to Pulsed Electromagnetic Field therapy that helped in healing of tissues, improved circulation and reduced inflammation. Thus PEMF can be an effective and safe adjuvant therapy for treating diabetic foot ulcers.
\end{abstract}

Keywords: Diabetic foot ulcers, limb amputation, wound debridement, wound healing, Pulsed electromagnetic field therapy.

\section{Introduction}

The life time risk of developing foot ulcer is $25 \%{ }^{1}$ with annual incidence $2-3 \%^{2}$ in diabetic population. Foot ulcer changes the quality of life in patients leading to devastating consequences like limb amputation A

\section{Corresponding Author: \\ Dr Amareswari V.H.}

Assistant Professor, Dept of Physiology, Rajarajeswari Medical College, Bengaluru, e-mail: amareswarivh@gmail.com million lower leg amputations are performed each year worldwide due to diabetes and every 30 second at least one lower limb is $\operatorname{lost}^{3}$.Around 100,000 leg amputations are carried out per year in India ${ }^{4}$.

Peripheral neuropathy and Ischemia from peripheral vascular disease are the major predisposing factors for the development of foot ulcers ${ }^{5}$ along with biomechanical changes in the foot. Diabetic peripheral neuropathy involves all three divisions of nervous system ${ }^{5}$. Due to loss of sensation any trivial injury is unnoticed by the patient. They are prone for repetitive trauma due excessive pressure points during weight bearing and ambulation. The autonomic neuropathy increases 
susceptibility to skin cracks and infection as the overlying skin becomes dry and fissured ${ }^{6}$. Hyperglycemia leads to endothelial cell dysfunction in peripheral arteries ${ }^{7}$. Atrophy of intrinsic muscles of foot leads to anatomical foot changes and deformities with development of high pressure points ${ }^{8}$. Abnormal non enzymatic glycosylation end products decrease synthesis of nitric oxide a vasodilator leading to endothelial dysfunction with alteration in extra cellular matrix integrity ${ }^{9}$. Disordered immune response prolongs the inflammation. Release of Inflammatory cytokines interferes with cell proliferation, wound closure and healing ${ }^{10}$. keratinocytes fail to reepithelialize the wound ${ }^{11}$. Failure of reepithelialization increase susceptibility to infections and damages the tissues leading to gangrene and limb amputation ${ }^{12}$.These amputations are potentially preventable. Prevention, multidisciplinary treatment and appropriate organization can lead to significant reductions in amputation rates up to $85 \%{ }^{13}$. Diabetic foot ulcers are conventionally treated by off loading and debridement ${ }^{14}$. But these do not act at cellular levels. Hyperbaric oxygen therapy ${ }^{15}$ though popular in improving local perfusion but has uncertain efficacy. Surgical therapies found to be costly. All these modalities increase the burden on the patient in terms of time consumption and cost. Pulsed electromagnetic therapyhas been used for tissue healing over last decade ${ }^{16}$. On exposure to electromagnetic fields in pulsed, non invasive manner on and off with a specific intensity and frequency local currents are induced. These induced currents then interacts with the wound currents or with cellular transduction signaling pathways in soft tissues ${ }^{17}$. It has beneficial effects on various functional aspects of wound repair such as proliferation of fibroblast and granulation tissue, epidermal cell migration, increased blood flow and edema reduction ${ }^{17}$. It also enhances microcirculation and microvasculature which has been linked with the enhanced healing of wounds ${ }^{18}$.As a result it is evident that the pulsed electromagnetic fields act as a potential, safe and an effective conservative management in promoting diabetic ulcer healing in clinical practice.

\section{Materials and Method}

Study design: Prospective observational study.

This study was conducted from Sep 2014- Aug 2015 at Rajiv Gandhi Government General Hospital after obtaining Institutional Ethics Committee clearance. Inclusion criteria: Thirty diabetic patients both men and women of age 40-60 years, foot ulcers of duration more than 4-6 weeks, Wagner's grading 1 (superficial ulcers) and Wagner's grading 2(Ulcer extension involving ligament, tendon, joint capsule, or fascia with no abscess or osteomyelitis) are participated .Exclusion criteria: Patients with uncontrolled DM, Wagner's grade 3, 4 and 5 , Neuroischemic ulcers, traumatic or venous ulcers, Peripheral vascular disease and those with Pacemakers are excluded from the study. Informed consent was obtained from all the patients. They were explained about the daily treatment protocol and follow up schedule and instructed to continue anti diabetic treatment, throughout the study period. Complete general, systemic and local examination carried out. The equipment consists of a controlled magnetic field system-portable type along with its accessories-a signal generator [Make systronics, model 1012 and sr. No 4588] and a monitoring meter assembly [oxford 50-0-50mA range]. The coil assemblies designed and fabricated at Madras institute of magneto biology The device provides an ultra low intensity (1500nTesla) about $1 / 40^{\text {th }}$ of normal earth's magnetic field at extremely low frequencies (ranging between 1 to $10 \mathrm{~Hz}$ ) for therapy. This ensures safety to the patient's .No radiation is involved and it is totally non-invasive. All patients included in the study group were subjected to Pulsed electromagnetic field therapy as per the protocol designed by Madras Institute of Magneto biology. The patient comfortably lies in the couch for 45 minutes keeping their foot with ulcers inside the magnetic field of the coil system every day for 6 days with a break of one day for 30 days, The equipment set at low current strength of $30 \mathrm{~m} \mathrm{~A}$, frequency of $10 \mathrm{~Hz}$, sine wave form and intensity of $1500 \mathrm{nT}$. Wound size and dimensions, tissue type, amount of exudation before and after treatment was compared. The longest and widest aspect of the wound surface is measured with ruler in cms. Depth measured by sterile metal probe placed perpendicular into the lowest section of the wound marked with marker pen read with a ruler in cms. The type of tissue present in the ulcer bed scored as: (4) Necrotic Tissue: (Eschar) black/brown tan tissue that adheres firmly to the wound bed (3) Slough: yellow or white tissue that adheres to the ulcer bed and ismucinous.(2) Granulation Tissue: pink or beefy red tissue with a shiny, moist, granular appearance. (1) Epithelial Tissue: New pink or shiny tissue (skin) that grows in from the edges or as islands on the ulcer surface. (0): Closed/Resurfaced: the wound completely covered with epithelium (new skin)". Amount of exudation is calculated by placing a butter (or) tracer paper spread on to the wound area and amount of soaking is seen 
and scored as None: 0, Light :1, Moderate: 2, Heavy: 3, Grading of tissue type and exudates amount is followed from Pressure Ulcers: Scale for Healing (PUSH)

Statistical Analysis: Data was analysed using student paired $t$-test $\mathrm{p}$ value $<0.05$ was considered statistically significant. Statistical software SPSS version 21 used for analysis.

\section{Results}

Table I: Demographic data and base line data (n) $=\mathbf{3 0}$

\begin{tabular}{|l|c|c|}
\hline Mean Age (years) & \multicolumn{2}{|c|}{$55.1 \pm 5.01$} \\
\hline Age range (years) & \multicolumn{2}{|c|}{$43-60$} \\
\hline Number of men & \multicolumn{2}{|c|}{23} \\
\hline Number of women & \multicolumn{2}{|c|}{7} \\
\hline Mean duration of Diabetes (yrs) & \multicolumn{2}{|c|}{$7.8 \pm 1.47$} \\
\hline Mean ulcer duration (months) & \multicolumn{2}{|c|}{$4.9 \pm 1.2$} \\
\hline \multirow{2}{*}{ Wagner's classification } & Grade 1 & Grade 2 \\
\cline { 2 - 3 } & 16 & 14 \\
\hline
\end{tabular}

The patients demographic data given in the table 1 shows that the study group included thirty patients (M: F, 23:7) with mean age of $55.06 \pm 5.01$ yrs. The mean duration of Diabetes is $7.8 \pm 1.47 \mathrm{yrs}$ and the mean duration of ulcer is $4.9 \pm 1.2$ months. Sixteen were grouped under Wagner's 1 and fourteen are grouped under Wagner'2 grading. None of the patients were complained of adverse effects and their compliance was good throughout course of the treatment. Percentage reduction in surface area as calculated as

(Initial surface area - final surface area X100)

Initial surface area

The patients showed overall $66 \% \pm 15 \%$ reduction in the wound surface area. Less than $50 \%$ reduction is reported in 2 of the patients. About 50-59\% reduction is noted in 6 patients, 11 patients showed 60-69\% reduction, 7 patients showed $70-79 \%$ reduction, 2 patients more than $90 \%$ reduction and 2 patients showed $80-89 \%$ reduction in the wound area. None reported any worsening of the symptoms. Tissue type changed from slough to granulation tissue in all patients and exudates amount reduced significantly.

Table 2: Comparison of healing Before and after treatment

\begin{tabular}{|c|c|c|c|c|c|}
\hline Variable & Group & $\mathbf{N}$ & Mean & SD & P-Value \\
\hline \multirow{2}{*}{ Surface Area } & Pre & \multirow{2}{*}{30} & 4.2 & 2.8 & \multirow{2}{*}{$0.0001^{* *}$} \\
\hline & Post & & 1.54 & 1.0 & \\
\hline \multirow{2}{*}{ Depth } & Pre & \multirow{2}{*}{30} & 0.66 & 0.19 & \multirow{2}{*}{$0.0001^{* *}$} \\
\hline & Post & & 0.33 & 0.2 & \\
\hline
\end{tabular}

Table 2 shows statistically significant reduction in the wound surface area and wound depth at the end of the therapy from the base line value $(* * \mathrm{P}-$ Value $<0.0001)$

Table 3: Comparison of healing Before and after treatment

\begin{tabular}{|c|c|c|c|c|c|}
\hline Variable & Group & $\mathbf{N}$ & Mean & SD & P-Value \\
\hline \multirow{2}{*}{ Tissue Type } & Pre & \multirow{2}{*}{30} & 3 & 0 & \multirow{2}{*}{$0.0001^{* *}$} \\
\hline & Post & & 1.76 & 0.61 & \\
\hline \multirow{2}{*}{ Exudate Amount } & Pre & \multirow{2}{*}{30} & 1.4 & 0.48 & \multirow{2}{*}{$0.0001 * *$} \\
\hline & Post & & 0.16 & 0.37 & \\
\hline
\end{tabular}

Table 3 shows statistically significant change in the tissue type and significant decrease in exudates amount at the end of the therapy from the base line value $(* * \mathrm{P}-$ Value $<0.0001)$ 


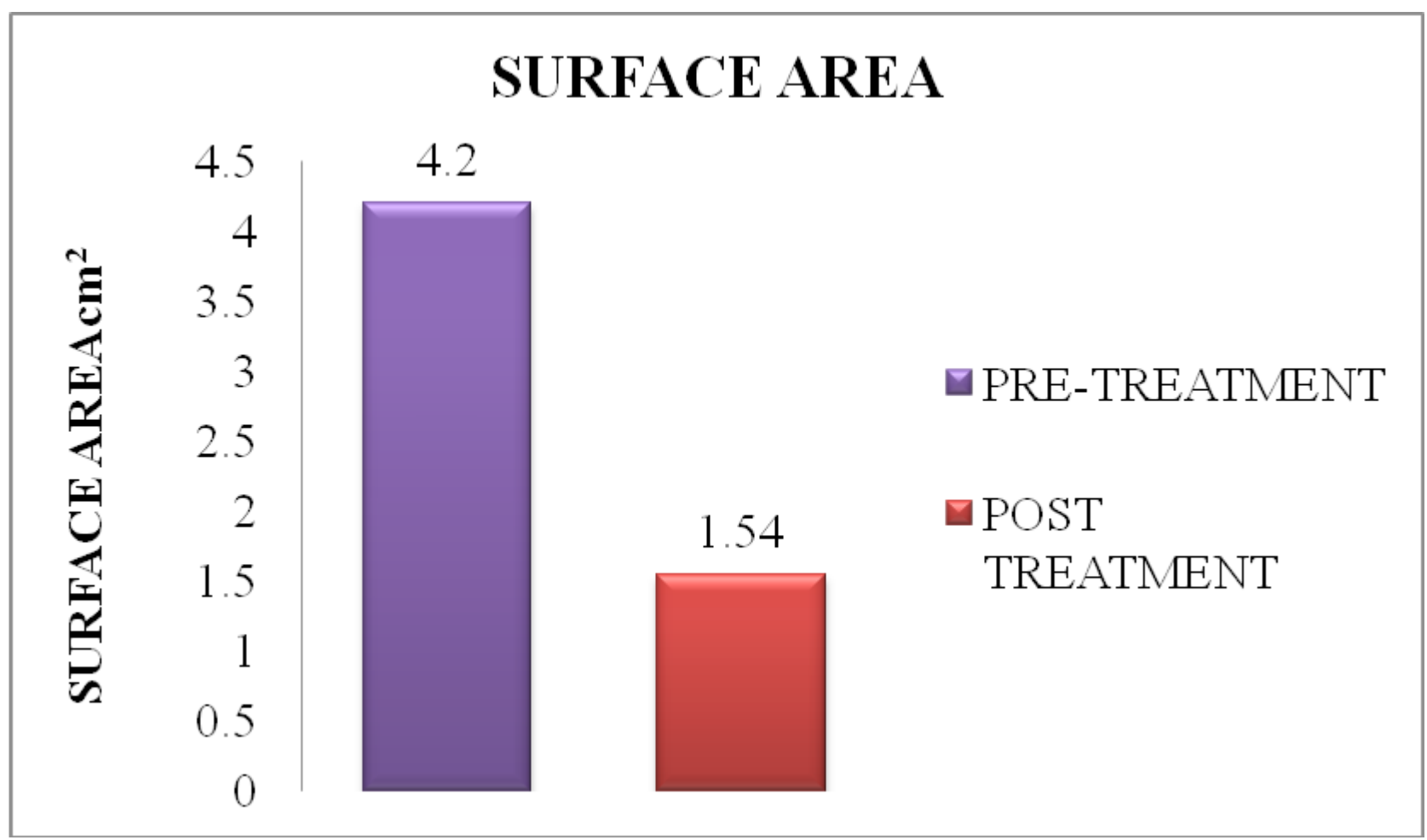

Graph 1. Comparison of means of ulcer surface area before and after PEMF

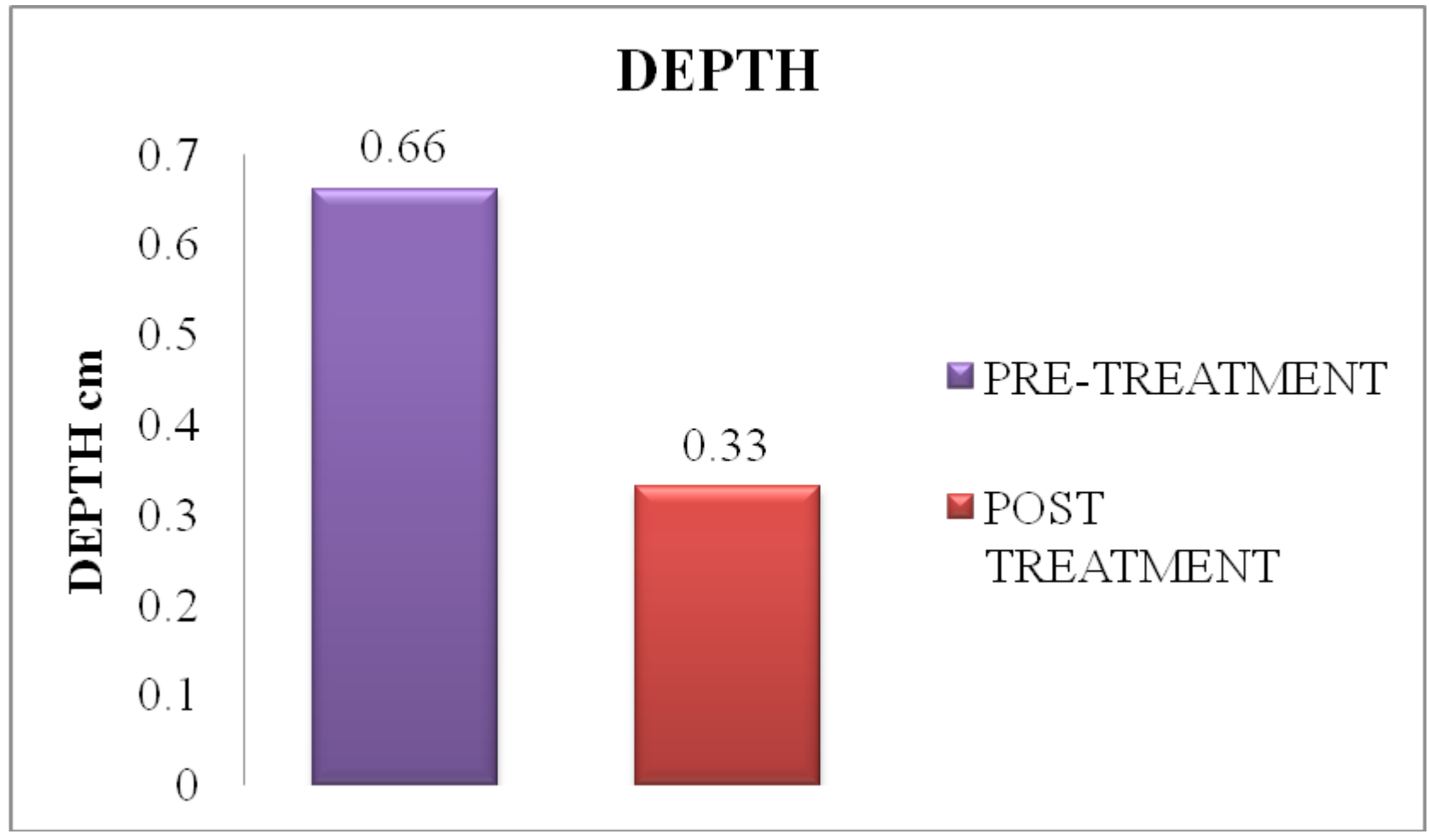

Graph 2. Comparison of means of ulcer depth before and after PEMF 


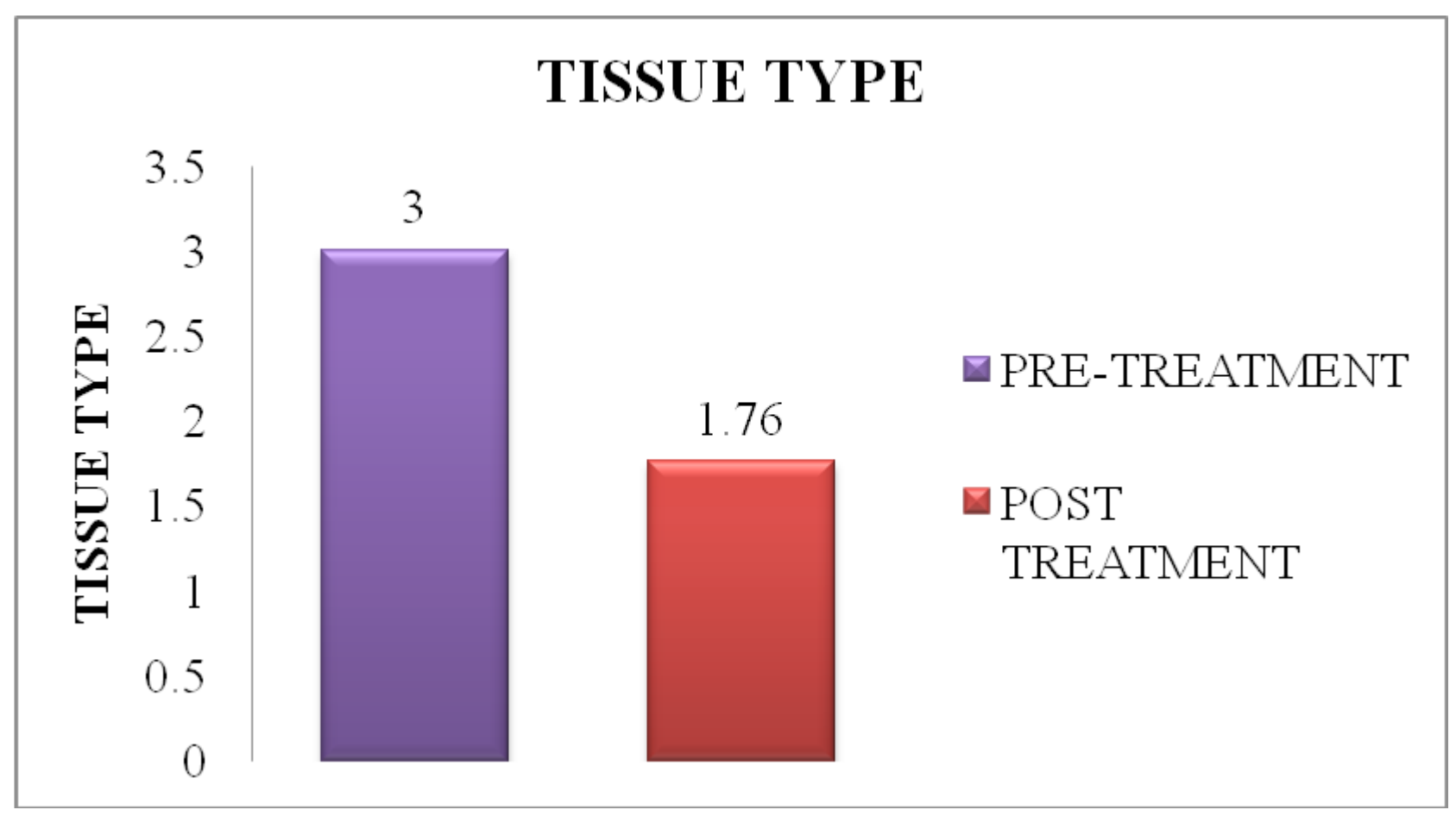

Graph 3. Comparison of means of ulcer tissue type before and after PEMF

\section{Discussion}

Though diabetic foot ulcers conventionally treated by debridement and off loading their efficacy remain uncertain. In this study portable non invasive equipment which delivers pulsed electromagnetic fields is used. This study showed significant reduction in wound surface area and dimensions which is consistent with the study by stiller et $\mathrm{al}^{19}$ where $47.7 \%$ reduction in ulcer surface area and significant reduction in wound depth. A randomized trial of case control study by Kenkre $\mathrm{JE}$ et $\mathrm{al}^{20}$ in primary care venous leg ulcers showed exposure to electromagnetic fields for 30 days has resulted in reduction in mean ulcer area and some ulcers completely healed. Pulsed electromagnetic field therapy for a duration of 90 days reported significant healing in venous ulcers (Ieran et $\mathrm{al}^{16}$ ). There was a change in tissue type from slough to granulation tissue in almost all the patients showing improvement in healing in this study which is consistent with the study by stiller et al ${ }^{19}$. Ian M Rawe et $\mathrm{al}^{21}$ observed a steady decrease in wound size as well as decrease in visible peri wound edema. In both the studies of Stiller et $\mathrm{al}^{19}$ and Ian M Rawe et $\mathrm{al}^{21}$ all the patients were well tolerated therapy without any adverse effects.. PEMF accelerated wound healing in chronic ulcers (Canaday and Lee et $\mathrm{al}^{22}$ ). PEMF therapy increase cellular metabolism, increase mitosis of various cells such as fibroblasts and endothelial cells by applying certain frequencies and intensity. This could be the reason for the improved healing of soft tissue in this study (Brette wade et $\mathrm{al}^{23}$ ). There are many in vitro studies showing diverse cellular responses to PEMF which are relevant to wound healing. Fibroblasts and epithelial cell cultures, on exposure to electric fields migrated perpendicular to the applied field. This could be the reason for healing in this study which involves the migration of fibroblasts and epithelial cells to the wound site. When locally exposed to magnetic fields, there was blood vessel relaxation (Smith et $\mathrm{al}^{24}$ ). A study by Ottani et $\mathrm{al}^{25}$, induced surgical wounds in rats on exposure to magnetic field therapy for 42 days resulted in greater and faster rate of wound healing. From these studies it is evident that PEMF was able to treat inflammation in diabetic ulcers and act as a non-invasive, low-cost, easyto-use complement or alternative to currently prescribed treatments thus this study showed that PEMF therapy is safe and effective in healing of diabetic foot ulcers.

\section{Conclusion}

The result of this study concludes that PEMF can be used effectively as a safe adjuvant treatment in diabetic 
foot ulcers. From various clinical and case studies it is evident that PEMF therapy linked positively with wound healing processes, improved circulation and reduced inflammation. Also it is noninvasive, portable and convenient to the patient without any side effects. There are certain limitations of our study such as the small sample size, inclusion of only grade 1 and 2 Wagner's ulcers, Non feasibility of prolonged treatment protocol. There is need for further case control studies to determine timing, duration and efficacy of electromagnetic therapy.

\section{Conflict of Interest: No}

\section{Source of Funding: Self}

Ethical Clearance: Taken from Institutional Ethics Committee, Madras Medical College.

\section{References}

1. Singh N, Armstrong DG, Lipsky BA: Preventing foot ulcers in patients with diabetes. J.A.M.A 2005; 293:217-228.

2. Reiber GE, Vileikyte L, Boyko EJ, del Aguila M, Smith DG, Lavery LA et al : Causal pathways for incident lower extremity ulcers in patients with diabetes from two settings. Diabetes Care 1999; 22:157-162.

3. Boulton A.J, Vileikyte L, Ragnarson-Tennvall G.et al. The global burden of diabetic foot disease. Lancet 2005; 366:1719-1724

4. Sharad K Pendsay. Contemporary management of the Diabetic foot. $1^{\text {st }}$ edition chapter 1 page 1 . New Delhi: Jaypee Medical publishers;2014.

5. Bowering CK: Diabetic foot ulcers: pathophysiology, assessment and therapy. Can Fam Phys 2001; 47:1007-1016

6. Warren Clayton Jr, Tom A. Elasy. A review of the pathophysiology, classification and treatment of foot ulcer in Diabetic patients. Clinical Diabetes 2009; 27:2.

7. Zochodone DW: Diabetic polyneuropathy: an update. Curr Opin Neurol 2008; 21:527-533.

8. Carine $\mathrm{Hm}$ et al. Muscle Weakness and Foot Deformities in Diabetes: Relationship to neuropathy and foot ulceration in Caucasian diabetic men, Diabetes Care 2004;27:7, pp1668-1673

9. Huijberts MS, Schaper NC, Schalkwijk CG : Advanced glycation end products and diabetic foot disease. Diabetes Metab Res Rev 2008; 24 (Suppl.
1) S19-S24.

10. Snyder, Robert J. "Treatment of non healing ulcers with allografts". Clinics in Dermatology 2005; 23(4): 388-95.

11. Foy, Yvonne; Li, Jie; Kirsner, Robert et al. "Analysis of fibroblast defects in extracellular matrix production in chronic wounds". Journal of the American Academy of Dermatology 2004; 50 (3): P168.

12. Mustoe, Thomas."Understanding chronic wounds: A unifying hypothesis on their pathogenesis and implications for therapy". The American Journal of Surgery. 2004; 187 (5): S 65.

13. Larsson J, Apelqvist J, Agardh C.D, et al. Decreasing incidence of major amputation in diabetic patients: A consequence of a multidisciplinary foot care team approach? Diabet. Med. 1995; 12: 770.

14. Armstrong DG, Lavery LA, Nixon BP, Boulton AJ: It's not what you put on, but what you take off: techniques for debriding and off-loading the diabetic foot wound. ClinInfect Dis 2004; 39: S92S99.

15. Faglia E, Favales F, Aldeghi A, Calia P, Quarantiello A, Oriani G. et al. Adjunctive systemic hyperbaric oxygen therapy in treatment of severe prevalently ischemic diabetic foot ulcer: a randomized study. Diabetes Care1996;19:1339-1343

16. Ieran $\mathrm{M}$, Zaffuto $\mathrm{S}$, Bagnacani $\mathrm{M}$, Annovi $\mathrm{M}$, Moratti A, Cadossi R. Effect of low frequency pulsing electromagnetic fields on skin ulcer of veous origin in humans: A double-blind study. J Orthop Res 1990; 8:276-282.

17. Lee RC, Canaday DJ, Doong H. A review of the biophysical basis for the clinical application electric fields in soft-tissue repair. J Burn Care Rehabil 1993; 14:319-335.

18. Julia C.Mckay, Frank S.Prato, Alex W.Thomas. A literature review: The effects of magnetic field exposure on blood flow and blood vessels in the microvasculature. Bioelectromagnetics 2007; 28:81-98

19. Stiller MJ, Pak GH, Shupack JL, Thaler S, Kenny C, Jondreau L.A portable pulsed electromagnetic field (PEMF) device to enhance healing of recalcitrant venous ulcers: A double-blind, placebo-controlledclinical trial. Br J Dermatol 1992; 127:147154.

20. Kenkre JE, Hobbs FD, Carter YH, Holder RL, 
Holmes EP.A randomized controlled trial of electromagnetic therapy in the primarycare management of venous leg ulceration. Fam Pract 1996; 13:236-241.

21. Ian M Rawe. Pulsed radio-frequency electromagnetic field therapy as an adjunct wound healing therapy Wounds international 2012; 3:(4) P32-34.

22. Canady DJ. Lee RC. Scientific basis for clinical applications of electric fields in soft tissue. In: Electromagnetic in medicine and Biology San Francisco Press, 1991; 275-91
23. Brett Wade. A Review of Pulsed Electromagnetic Field (PEMF) Mechanisms at a Cellular Level: A Rationale for Clinical Use. American Journal of Health Research. 2013; Vol. 1, No.3, pp. 51-55

24. Smith T, Wong-Gibbons D, Maultsby J. Micro circulatory effects of pulsed electromagnetic fields. J. Orthop Res 2004; 22:80-84

25. Ottani V, Depasquale V, Govani P, Franchi M, Zaniol P, Ruggar A. Effects of pulsed extremilylow frequency magnetic fields on skin wounds in the rat. Bioelectro magnetics 1998; 9:53-62. 